\title{
A Comparison of the Relation of Depression, and Cognitive, Motor and Functional Deficits in Chronic Stroke Patients: A Pilot Study
}

Amin Ghaffari*1, Malahat Akbarfahimi ${ }^{1}$, Bijan Forough ${ }^{2}$

1- Department of Occupational therapy, School of Rehabilitation, Iran University of Medical Sciences, Tehran, Iran 2- Department of Physical and Rehabilitation Medicine, School of Medicine, Iran University of Medical Sciences, Tehran, Iran

\begin{abstract}
Aim and background: One of the most important psychological disorders after stroke is depression, which leads to reduced quality of life, optimal rehabilitation failure, loss of cognitive tasks and decrease in the recovery process. In this research, relation between patterns of depression and cognitive, motor and function deficits in people with chronic stroke was studied.

Methods and materials: In a pilot cross-sectional study, 40 patients with chronic stroke (more than 6 months) were enrolled. Depression (Beck Depression Inventory), cognition (attention test TMT-A \& B and Wechsler memory), motor (Motorcity index), basic activities of daily living (Barthel scale) and instrumental activities of daily living (Lawton scale) were evaluated.

Results: The results of the study revealed a significant positive correlation between post stroke depression and verbal memory $(r=0.440, P<.05)$, attention $(r=0.615, P<.05)$, motor function $(r-$ $0.368 ، P<.05)$, independence in basic activities of daily living $(r=0.781 ، P<.05)$ and instrumental activities of daily living $(r=0.741, P<.05)$.

Conclusion: According to the findings, further studies of factors affecting post stroke depression (PSD) clinical and practical aspects are necessary. Cognitive rehabilitation programs with motor rehabilitation can decrease depression and gain independence in activities of daily living and more participation in society activities.

Keywords: Depression; Cognitive deficits; Motor deficits; Functional deficits; Chronic stroke
\end{abstract}

Corresponding author:

Amin Ghaffari

School of Rehabilitation Sciences, Iran University of Medical Sciences, Tehran, Iran

E-mail: ghaffari.a@kar.iums.ac.ir

Receive date: 2017-06-10 | Accept date: 2017-09-12 | Publish date: 2017-10-01

DOI: 10.7575/aiac.abcmed.17.05.04.01 


\section{Introduction}

Stroke in cerebrvascular diseases (CVD) is a major health concern in the elderly (1); the third cause of mortality in the world and one of the most common disabling neurological diseases in adults (2). Effects of a stroke, based on the severity and location of the lesion, are varied (1). Complications of stroke include: physical damage such as hemiplegia or monoplegia, urinary incontinence, impaired visual field, numbness, paralysis of brain nerves or aphasia and psychological disorders such as depression, anxiety and cognitive impairments (1).

The most common psychological disorder is post stroke depression (PSD) (1,3-4). Depression is a complex complication after a stroke that increases mortality, decreases function, reduces quality of life, prolongs therapy requirements, reduces the recovery process, cognitive, and neurological function, hinders optimal rehabilitation therapy, increases therapy costs and delays returning to work and social participation (5-11). Therefore, identifying factors contributing to the incidence of targeted actions in this regard is necessary. Prevalence of PSD in the first year after stroke is $20-50 \%$ and according to some references it is most common in the first 6 months (12). In a three-year study, patients experienced two peaks one after the first three months and the next 24 months after stroke (13).

There are no consensus diagnostic criteria defining PSD yet. Many studies have been conducted to determine the pathology of depression after stroke (14). In conclusion, there are two hypotheses: biological (PSD due to structural damage following brain stroke) (15) and psychological (PSD deal of patients with disability and psychosocial problems following stroke) (16). Some researchers believe that the importance of these hypotheses is equal. "Vascular" hypothesis, the dominant hypothesis, has also been recently presented and discussed (14). The factors that can influence the cause of PSD not only show communication circuit of neurons and effective centers in controlling mood and cognitive in the brain but also the clinical application is necessary. Thus, this study aimed to examine the correlation of depression with cognitive, motor and functional impairments in chronic stroke patients.

\section{Method and materials}

Study participants were 40 patients with stroke for more than 6 months of their damage. The mean age of the study population was $52.55 \pm 12.23$ years. This study was a descriptive analysis study. During October to March 2015 subjects to sampling available after receiving permission from the Student Research Center Iran University of Medical Sciences were evaluated in the clinics of Occupational Therapy, Rehabilitation Clinic of Iran University of Medical Sciences, Department of Neurology and Physical Medicine Rehabilitation in Firouzgar Center (ethic code:IR.IUMS.REC1395.9411355005). Inclusion criteria were right-handed, 6 to 36 months after the stroke, stroke only in one hemisphere, the first stroke, and the age group between $30-80$ years. Exclusion criteria were: antidepressants and treatments for brain stimulation, existence of neurologic disorders (Alzheimer's, Parkinson's, severe Traumatic Brain Injury, epilepsy, history of injuries, brain tumors, dementia of any lesions and abnormalities in the central nervous system), history of TIA (transient ischemic attack), depression before stroke (according to the patient's family history and taking antidepressant medication or hospitalization). Assessment tools: Beck Depression Inventory was used to assess depression, Wechsler memory scale evaluation to assess verbal memory. TMT(A-B) was used to assess attention. Motorcity index was used to evaluate motor levels. To assess the basic activities of daily life, we used Barthel test and 
for assessment of instrumental activities of daily life, Lawton test was used.

\section{Results}

\begin{tabular}{lll}
\hline \multicolumn{2}{l}{ Demographic characteristics } & Patients with chronic stroke \\
\hline \multirow{2}{*}{ Sex } & Man & $40 \%$ \\
\cline { 2 - 3 } & Woman & $60 \%$ \\
\hline \multirow{2}{*}{ Education } & Under Diploma & $32.5 \%$ \\
\cline { 2 - 3 } & Diploma & $32.5 \%$ \\
\cline { 2 - 3 } Material statue & Above Diploma & $35 \%$ \\
\cline { 2 - 3 } & Single & $7.5 \%$ \\
\hline \multirow{2}{*}{ Job } & Married & $92.5 \%$ \\
\cline { 2 - 3 } & Housewife & $37.5 \%$ \\
\cline { 2 - 3 } & Retired & $40 \%$ \\
\hline Affected side & Practitioner & $22.5 \%$ \\
\cline { 2 - 3 } & Right & $35 \%$ \\
\hline
\end{tabular}

Table 1: demographic characteristics in chronic stroke $(N=40)$

In Table 2, studied variables (mean and standard deviation) are shown:

Descriptive Statistics

\begin{tabular}{llll}
\hline Variables & Mean & Std. Deviation & $\mathrm{N}$ \\
\hline Depression-Beck & 17.3250 & 10.80927 & 40 \\
Barthel (BADL) & 73.2500 & 19.66221 & 40 \\
Lawton (IADL) & 4.3000 & 2.10250 & 40 \\
Weksler (Memory) & 9.0750 & 1.52564 & 40 \\
TMT-A(Attention) & 2.3000 & .56387 & 40 \\
TMT-B(Attention) & 2.2750 & .50574 & 40 \\
Motor-Arm & 57.3750 & 19.77007 & 40 \\
Motor-Leg & 63.3500 & 17.37601 & 40 \\
Motor-Side & 60.5625 & 15.74606 & 40 \\
\hline
\end{tabular}

Table 2: Descriptive Statistics in chronic stroke ( $\mathrm{N}=40$ studies) 
In table 3 using the Pearson correlation coefficient between depression and cognitive, motor and functional deficits:

\begin{tabular}{|c|c|c|c|c|c|c|c|c|c|}
\hline & & $\begin{array}{l}\text { Barthel } \\
\text { (BADL) }\end{array}$ & $\begin{array}{l}\text { Lawton } \\
\text { (IADL) }\end{array}$ & $\begin{array}{l}\text { Weksler } \\
\text { (Memory) }\end{array}$ & $\begin{array}{l}\text { TMT-A } \\
\text { (Attention) }\end{array}$ & $\begin{array}{l}\text { TMT-B } \\
\text { (Attention) }\end{array}$ & $\begin{array}{l}\text { Motor } \\
\text { Arm }\end{array}$ & $\begin{array}{l}\text { Motor } \\
\text { Leg }\end{array}$ & $\begin{array}{l}\text { Motor } \\
\text { Side }\end{array}$ \\
\hline & $\begin{array}{l}\text { Pearson } \\
\text { Correlation }\end{array}$ & 0.781 & 0.741 & 0.440 & 0.615 & 0.551 & 0.275 & 0.397 & 0.368 \\
\hline $\begin{array}{l}\text { Depression } \\
\text { (Beck }\end{array}$ & $\begin{array}{l}\text { Sig. (2- } \\
\text { tailed) }\end{array}$ & 0.000 & 0.000 & 0.004 & 0.000 & 0.000 & 0.086 & 0.011 & 0.020 \\
\hline Scale) & $\mathbf{N}$ & 40 & 40 & 40 & 40 & 40 & 40 & 40 & 40 \\
\hline
\end{tabular}

Table 3: Pearson correlation between depression and other variables

There was a significant correlation between depression and cognitive impairments (memory and attention), motor side (arm + leg) and functional (basic activities of daily life (Barthel) + instrumental activities of daily life(Lawton)) ( $p<.05)$.

\section{Discussion}

Depression is a common symptom of many neurologic disorders, but often not diagnosed and treated. Mood changes in depression as inability to experience happiness (controlled by the limbic system), feelings of hopelessness and worthlessness (controlled by the dorsolateral frontal cortex), feel guilty and in severe cases may cause suicidal thoughts (1,17-18). Affective disorders in depression include crying, change in body languages and avoiding eye contact. Apathy, loss of desire to initiation tasks (controlled by the anterior cingulate cortex and their respective structures) are also other symptoms. Changes in cognitive with depression are disorders in executive functions and visuospatial skills. Changes in verbal expression, including decline in the speed and volume of speech and emotional states related to it $(1,17)$. Depressive symptoms resulting from changes in the autonomic nervous function of the hypothalamus are appetite, sleep, energy levels, libido, mood changes during the day.
Also, the slowdown of the motion and gait, drooping shoulders, bent head, decreased gestures and visible catatonia are due to damage or abnormalities in the basal ganglia. Damage or disruption suprachiasmatic nucleus cause seasonal depression (19-20). The evidence from the past 15 years studies showed a significant relationship between unipolar depression and cognitive impairments (21). Depressed patients suffer from moderate to severe cognitive impairment degrees. Most reported cognitive impairments are in attention, concentration, recently memory, working memory, and executive functions (22). These findings are in line with our study.

Some authors linked slow metabolism and reduction in cerebral blood flow, especially in the prefrontal cortex, internal and external, anterior cingulate, anterior insula (21) and reduced volume of gray matter temporal lobes of the lower left orbitofrontal and right dorsolatrall prefrontal, left hippocamp, the cingulate and thalamus with development of cognitive impairment associated with depression (23).

In Irfan et al. study, 40 patients with stroke were examined. Results showed a significant correlation between cognitive impairments and depressive symptoms, and the language was reported as the most important prognostic 
factor for depression (24). These findings are in line with our study.

Studies on the correlation between PSD and independence in activities of daily living are controversial due to confounding variables. In a review article, 1982 studies, mostly on PSD depression, used SDS ${ }^{1}$, HAM-D ${ }^{2}$ or $\mathrm{PSE}^{3}$ criteria; the results showed significant correlation between depression and dysfunction in $\mathrm{ADL}^{4}$ such as dressing, eating, walking, orientation, expressed needs, reading and writing, and cleaning room (1). In another study on 64 stroke patients, ADL independence in depressed patients with SDS score was equal to or more than 50 than non-depressed patients. These findings are in line with our study (25). Appelros et al. determined the factors that increase or decrease satisfaction in stroke patients; ability of motor function increased satisfaction and depression as well as dependence on ADL which in turn decreased satisfaction (26). These findings are in line with our study.

We recommend further studies on both acute and chronic stroke patients as time is important in recovery after stroke.

\footnotetext{
${ }^{1}$ self-rating depression scale

${ }^{2}$ Hamilton Depression Rating Scale

${ }^{3}$ Present State Examination

${ }^{4}$ Activity Daily Living
} 


\section{References}

1. Tateno A, R.R., The Effect of Poststroke depression on recovery from stroke. PSYCHOGERIATRICS, 2002. 2: p. 73-84.

2. Schapira, A.H.V., E. Brane, and S. DIMauro, Neurology and Clinical Neuroscience. 1 ed. 2007, philadelphia: mosby. 235--247.

3. Wolfe, C.D., The impact of stroke. Br Med Bull, 2000. 56(2): p. 275-86.

4. Narushima, K. and R.G. Robinson, The effect of early versus late antidepressant treatment on physical impairment associated with poststroke depression: is there a time-related therapeutic window? J Nerv Ment Dis, 2003. 191(10): p. 645-52.

5. Lawrence, E.S., et al., Estimates of the prevalence of acute stroke impairments and disability in a multiethnic population. Stroke, $2001.3:(6) 2 p .1279-84$.

6. Robinson, R.G., Poststroke depression: prevalence, diagnosis, treatment, and disease progression. Biol Psychiatry, 2003. 54(3): p. 376-87.

7. Narushima, K. and R.G. Robinson, Stroke-related depression. Curr Atheroscler Rep, 2002. 4 :(4)p. 296303.

8. Nys, G.M., et al., Early cognitive impairment predicts long-term depressive symptoms and quality of life after stroke. J Neurol Sci, 2006. 247(2): p. 149-56.

9. Paolucci, S., et al., Poststroke depression and its role in rehabilitation of inpatients. Arch Phys Med Rehabil, 1999. 80(9): p. 985-90.

10. Joubert, J., et al., Risk factor management and depression post-stroke: the value of an integrated model of care. J Clin Neurosci, 2006. 13(1): p. 84-90.

11. Mitchell, P.H., et al., Living well with stroke: design and methods for a randomized controlled trial of a psychosocial behavioral intervention for poststroke depression. J Stroke Cerebrovasc Dis, 2008. 17(3): p. 109-15.

12. Dafer, R.M., et al., Poststroke depression. Top Stroke Rehabil, 2008. 15(1): p. 13.21-

13. Astrom, M., R. Adolfsson, and K. Asplund, Major depression in stroke patients. A 3-year longitudinal study. Stroke, 1993. 24(7): p. 976-82.

14. Dieguez, S., et al., Is poststroke depression a vascular depression? J Neurol Sci, 2004 :(2-1)226 .p. 53-8.

15. Biran, I. and A. Chatterjee, Depression with anosognosia following a left subcortical stroke. Clin Neurol Neurosurg, 2003. 105(2): p. 99-101.

16. Nys, G.M., et al., Early depressive symptoms after stroke: neuropsychological correlates and lesion characteristics. J Neurol Sci, 2005. 228(1): p. 27-33.

17. Drevets, W.C., Neuroimaging and neuropathological studies of depression :implications for the cognitiveemotional features of mood disorders. Curr Opin Neurobiol, 2001. 11(2): p. 240-9.

18. Robinson, R.G., et al., A two-year longitudinal study of post-stroke mood disorders: dynamic changes in associated variables over the first six months of follow-up. Stroke, 1984. 15(3): p. 510-7.

19. Kalia, M., Neurobiological basis of depression: an update. Metabolism, 2005. 54 5)Suppl 1): p. 24-7.

20. Walter, H., et al., Increased left prefrontal activation in patients with unipolar depression: an eventrelated, parametric, performance-controlled fMRI study. J Affect Disord, 2007. 101(1-3): p. 175-85.

21. Hosking, S., N. Marsh, and P. Friedman, Depression at 3-months poststroke in the elderly: Predictors and indicators of prevalence. Aging Neuropsychology \& Cognition, 2000. 7(4): p. 205-216. 
22. Castaneda, A.E., et al., Cognitive functioning in a population-based sample of young adults with a history of non-psychotic unipolar depressive disorders without psychiatric comorbidity. J Affect Disord, 2008. 110(1-2): p. 36-45

23. Vasic, N., et al., Gray matter reduction associated with psychopathology and cognitive dysfunction in unipolar depression: a voxel-based morphometry study. J Affect Disord, 2008. 109(1-2): p. 107-16.

24. Uzma Irfan,rt al., Relationship between Cognitive Impairment and Depressive Symptoms. Journal of Medical Sciences (2011); 4(3): 122-127

25. Sinyor, D., et al., Post-stroke depression: relationships to functional impairment, coping strategies, and rehabilitation outcome. Stroke, 1986. 17(6): p. 1102-7.

26. Appelros, P. and M. Viitanen ,Prevalence and predictors of depression at one year in a Swedish population-based cohort with first-ever stroke. J Stroke Cerebrovasc Dis, 2004. 13(2): p. 52-7. 